\title{
ASOCIACIÓN COLOMBIANA DE TERAPIA OCUPACIONAL
}

\section{Informe de Junta Directiva (Noviembre 1996 - Marzo 1999)}

Presidente T.O.: Sylvia Cristina Duarte Torres

El presente informe tiene el objetivo de dar a conocer las diferentes acciones realizadas durante estos dos años y cinco meses a fín de contribuir a la misión de la Asociación:

\section{MISIÓN}

"La Asociación Colombiana de Terapia Ocupacional es un grupo de profesionales en Terapia Ocupacional, sólido, que hace presencia en las actividades de tipo, científico, legislativo, cultural y social, a fín de velar por los derechos e intereses de la Terapia Ocupacional y sus profesionales: manteniendo un alto reconocimiento con las instituciones gubernamentales y no gubernamentales a nivel Nacional $e$ Internacional".

Durante esta gestión se tuvieron varios frentes de trabajo:

\section{EDUCACIÓN CONTINUADA}

El gran objetivo para este periodo fue fortalecer al Terapeuta Ocupacional Colombiano y dar a conocer las experiencias y conocimientos de los profesionales Nacionales.

Durante el año 1997 se realizaron conferencias mensuales, el último miércoles de cada mes, en el primer semestre la sede fue la Universidad Manuela Beltrán y el promedio de asistentes fué de 75 personas, algunos de los temas de las conferencias fueron: 
- Madurez y Aprendizaje

- Musicoterapia

- Rehabilitación del sordo - ciego

En el segundo semestre la sede fue la Escuela Colombiana de Rehabilitación, el promedio de asistentes fue de 15 personas y algunos de los temas tratados fueron:

- Salud mental comunitaria

- Tecnología y ferulaje

- Rehabilitación sexual

Para finalizar en el mes de octubre se realizó un curso descentralizado "Madurez Neurodesarrollo y Aprendizaje" en a ciudad de Neiva para 40 personas planeado por la vocal fuera de sede y organizado por el comité científico.

En 1998 debido a la poca acogida de las conferencias mensuales se decide organizar para el primer semestre un seminario de dos dias y medio sobre "Administración y Marketing" en las instalaciones del Club Militar, el número de asistentes llegó a 42 personas.

Durante el segundo semestre se canalizaron todas las estrategias a la organización del "XI Congreso Nacional de Terapia Ocupacional" y "Primer Salón de Exhibiciones", realizado en en Centro de Convenciones Calatrava en Bogotá, asistieron cerca de 350 personas a los módulos de Salud, Educación, Trabajo e Interés General.

En el primer semestre de 1999 se organizó un evento: sobre Juego y Guías de Atención en Terapia Ocupacional realizado en el Hotel La Fontana con asistencia de cerca de 50 personas.

\section{CELEBRACIÓN DE LOS 25 AÑOS DE LA ASOCIACIÓN}

Se realizaron tres celebraciones:

- La primera en Bogotá con 150 personas en el Hotel La Fontana, condecorando a los fundadores de la Asociación, a los expresidentes de la misma y nombrando a la Terapeuta Ocupacional Alicia Trujillo Rojas SOCIA HONORA- 
RIA, realizando un papel sobre nuestra posición en la Educación, en la Salud, en el Trabajo y en la Academia, además de una breve historia de la ACTO y del impacto de los Terapeutas Ocupacionales en Colombia.

Sociedades Científicas hace entrega de un pergamino por los 25 años de nuestra Asociación.

- La segunda en Santa Marta, asistieron 25 personas, se desplazó un representante de Junta y se realizaron conferencias en el área de Pediatría.

- La tercera en Neiva asistieron 35 personas, se desplazó un representante de junta y se dieron conferencias sobre Neurología.

\section{PROMOCIÓN DE LA PROFESIÓN DE TERAPIA OCUPACIONAL}

Para tal fín se utilizaron varias estrategias para promocionar y divulgar nuestra profesión en: Programas radiales en unión con la Secretaría de Salud; se realizaron 3 programas radiales en Caracol sobre la acción del Terapeuta Ocupacional en las áreas de Reumatología, problemas de Aprendizaje y Juego, y en la cadena Santa Fe 2 programas dirigidos a la comunidad sobre Artritis Reumatoidea y Problemas de Aprendizaje.

Se contactó la separata de Educación de El Tiempo para poder sacar un artículo sobre esta profesión que es?, donde estudiar, dónde se puede trabajar, y cual es el perfil del candidato. Se promocionó todo evento realizado con pauta publicitaria en separata social, de salud y de Educación para un total de 8 avisos.

Se sacaron artículos publicitarios tales como: Mugs, lápices, esferos, metros, agendas telefónicas, bolas anti-stress, memos adhesibles, escudos y bolsas de basura para carro.

\section{REVISTA OCUPACIÓN HUMANA}

Teniendo en cuenta las quejas verbales de los socios por el cambio constante de la carátula de la revista, se realiza un reglamento interno para el comité editorial y este aspecto lo decide el mismo comité, se entregan las dos ediciones anuales pero con dificultades de tiempo por las editoriales. 
El incremento del número de artículos es significativo pero en este aspecto es necesario hacer un llamado para que se puedan sacar 4 ejemplares en el año y no tener que devolver algunos artículos por falta de bibliografía, de actualización y de presentación. El comité editorial que nos acompanó durante nuestra gestión estuvo conformado por: T.O. Martha Torres de Tovar, T.O. Elvia Cuartas Nieto, T.O. Margarita González de Uribe, y como representante de Junta Directiva la T.O. Gloria Stella Sánchez, todas continúan excepto la T.O.Martha Torres de Tovar por sus numerosos compromisos laborales, quedando una vacante.

\section{BOLETÍN TRIMESTRAL}

Se sacaron 8 boletines en este tiempo, es un medio importantísimo para mantener informados a los socios sobre cursos, especializaciones, becas, bolsa de empleo y acciones realizadas en los diferentes comités, sería muy importante que se pudiera sacar bimensual para que estas informaciones sean oportunas en todo el país y el socio se dé cuenta de lo que está pasando, es otro de los beneficios de ser socio.

\section{ASOCIADOS}

En 1996 habían 114 afiliados de los cuales 46 se encontraban a paz y salvo, en la actualidad se encuentran 274 de los cuales hay 160 a paz y salvo, sin embargo se sigue observando que se aceptan varias hojas de vida de estudiantes y profesionales que nunca llegan a implementar su condición de socio por no pagar ni la inscripción, ni el mantenimiento anual, por eso se dio en los cursos y en los congresos la gran diferencia de ser socio a no serlo en el valor de la inscripción.

La estrategia que se recomienda seguir es:

- Valor del formulario de inscripción $\$ 3.000$

- Valor de la inscripción $\$ 85.000$

- Valor de la anualidad $\$ 75.000$

A fín de seguir consintiendo al socio antiguo y que no se le incrementa a la anualidad, esto sería para: 
Socio activo:

Valor de la inscripción $\$ 85.000$

Valor de la anualidad $\$ 75.000$

Total: $\$ 160.000$

Socio adherente:

Valor del formulario igual

Valor de la inscripción $\$ 60.000$

Valor de la anualidad $\$ 50.000$

Total $\$ 110.000$

Y poder continuar pagando en 3 cuotas consecutivas la anualidad a fin de facilitar el pago por el no uso de tarjetas de crédito.

Se llevó a cabo el plan amigos para antiguos socios que deseaban reincorporarse para lo cual se obtuvo un moderado éxito permitiendo acercar a personas de mucha trayectoria y valiosas para nuestra asociación, la junta directiva establece el premio a los mejores socios del año por su participación, compromiso y dedicación a la asociación, a 4 profesionales destacados por sus acciones, dándoles como premio el pago de su anualidad 1999, ellos fueron en 1998 Aleida Fernández, Maritza Ferro, Alicia Trujillo y Solangel García.

\section{REQUISITOS ESENCIALES PARA UN SERVICIO DE TERAPIA OCUPACIONAL}

Debido a que el primer documento es muy general y no especifica cada una de las áreas de intervención del Terapeuta Ocupacional y por niveles de complejidad, el Centro de Gestión Hospitalaria convocó a la asociación y por intermedio de ella a cada una de las escuelas formadoras para pasar una propuesta para modificar dicho documento, la Asociación aprovecha la coyuntura para realizar un seminario de capacitación para los docentes de las universidades a fin de incrementar motivación y participación en dicha propuesta y coordinar en conjunto con el Centro de Gestión Hospitalaria las propuestas de los coordinadores de redes de Bogotá y los Terapeutas que laboran a nivel privado, esta última propuesta que es la unificada de los tres grupos debe ser consolidada antes de junio 15 del presente. 


\section{CLASIFICACIÓN ÚNICA DE PROCEDIMIENTOS EN SALUD}

En la actualidad el Ministerio de Salud propone revisar dicha clasificación y mandar las diferentes objeciones y propuestas de Cambio antes de mayo 30, ante dicha emergencia se hace necesario contratar a 2 expertos para realizar la modificación en conjunto o con la asesoría de las personas encargadas del Ministerio pues no aparecen muchos de los procedimientos que fueron remitidos en el año 98 y los cuales fueron omitidos o pasados a otra profesión, en la sede reposan las copias de los comunicados efectuados realizados a la División de Asuntos Económicos del Ministerio de Salud lo cual ocasiona dificultades en nuestro ejercicio profesional.

\section{BIBLIOTECA}

Se realiza la compra de dos bibliotecas en madera debido a la cantidad de libros que se tienen para el uso exclusivo de los socios, además se obtienen libros nuevos en el área de problemas de aprendizaje, revistas Australianas de Terapia Ocupacional , la revista Argentina Materia Prima y la revista Española APETO, además en las dos últimas revistas de la Ocupación Humana se sacaron por temas lo que se encuentra en nuestra biblioteca.

\section{COMITÉ DE ÉTICA}

Durante 1998 se dio inicio al funcionamiento del Comité de Ética a partir de agosto con una reunión quincenal, estableciéndose el siguiente comité:

T.O. Alicia Trujillo Rojas

T.O. Maria Eugenia Caicedo

T.O. Adriana Orduz de Cáceres

T.O. Aída Navas de Serrato

T.O. Margarita González de Uribe

A este comité debe asistir un representante de universidades y un representante de junta directiva. 


\section{DOCUMENTO DE REQUISITOS ĖSENCIALES PARA L̇A CREACIÓN Y FUNCIONAMIENTO DE PROGRAMAS DE PREGRADO DE TERAPIA OCUPACIONAL}

En conjunto con el ICFES y por iniciativa del mismo, se realizaron 2 seminarios (10. en noviembre de 1997 en Bogotá, y otro en febrero de 1998 en Bucaramanga) para trabajar sobre la actualización de este documento en conjunto con representantes de las 14 universidades que aparecen registradas ante el ICFES a nivel profesional y tecnológico, una tercera reunión fue asumida por la ACTO donde se llevó a cabo un taller sobre los aspectos de definición, perfil y futuro del Terapeuta Ocupacional y finalmente se establecieron los comités de redacción y de Expertos, este documento se finalizó en octubre de 1998 y fue entregado 3 ejemplares a cada una de las universidades y en la sede de la asociación quedan 35 copias.

\section{FEDERACIÓN MUNDIAL DE TERAPIA OCUPACIONAL}

Las delegadas por Colombia durante este periodo fueron las Terapeutas Ocupacionales Margarita González de Uribe y la Terapeuta Ocupacional Alicia Trujillo Rojas. Se pone al día con la WFOT 1995, 1996 Y 1997 por 16 socios inscritos a la Federación, en la actualidad hay 40 socios inscritos y se debe la cuota 1998 y 1999, la delegada principal tiene la lista de los socios y la revista de 1998 y 1997 fueron entregadas a cada uno de los socios, al igual el carnet.

El Colegio Mayor de Nuestra Señora del Rosario hace entrega de su plan curricular con copia y esté es enviado àl Comité de Educación de la Fedéración para que dicha Escuela formádora sea aprobada, en la actualidad no se há recibido contestación, es necesario comunicarse con la actual directora de Educación porque en mayo de 1998 en Ottawa la junta directiva de la Federación cambió y no hubo representación de Colombia en dicha reunión.

En 1998 se realiza monitoreo quinquenal de las Escuelas aprobadas por la WFOT que son: Universidad Nacional de Colombia, Escuela Colombiana de Rehabilitación y la Universidad del Valle.

Se actualizaron datos y la correspondencia llega a la dirección de la delegáda por ser la sede confusa en comunicación.

SYLVIA CRISTINA DUARTE TORRES

Marzo 31 de 1999 